\title{
Estratégias de Coping no Contexto Laboral: uma Revisão Integrativa da Produção Científica Brasileira e Internacional
}

\author{
Jaqueline Marques Muller ${ }^{1}$, Narbal Silva ${ }^{2}$, Andréa Duarte Pesca ${ }^{3}$
}

${ }^{1}$ http:/ / orcid.org/0000-0002-8245-7180 / Universidade Federal de Santa Catarina (UFSC), Brasil
${ }^{2}$ http:// orcid.org/0000-0003-2841-3440 / Universidade Federal de Santa Catarina (UFSC), Brasil
${ }^{3}$ http:// orcid.org/0000-0002-5471-3810 / Universidade Federal de Santa Catarina (UFSC), Brasil

Resumo

Trata-se de uma revisão integrativa que teve como objetivo investigar as estratégias de coping no trabalho, a fim de ampliar a compreensão do conceito na relação indivíduo-trabalho-organização. O método adotado seguiu duas etapas principais: 1) busca sistemática, análise e seleção das publicações nas bases de dados Web of Science, Lilacs, Scielo e Scopus, considerando todo o período de publicações, que totalizou 592 artigos; e 2) revisão das 28 publicações selecionadas na primeira etapa. Os critérios de inclusão foram investigações acerca de coping no trabalho e estudos disponíveis para leitura na íntegra. Os resultados demonstram que a promoção de ações educativas para a gestão do estresse e a oferta de suporte social são imprescindíveis à saúde no contexto organizacional. Também são necessárias intervenções focadas no ser humano, como também nas relações entre gestores e trabalhadores. No contexto organizacional, as descobertas apontam para a necessidade de mudanças das condições físicas e ambientais, visando promover qualidade de vida, bem-estar e felicidade.

Palavras-chave: profissionais, trabalhadores, estresse no trabalho, estratégias de enfrentamento no trabalho.

\section{Coping Strategies in the Workplace: an Integrative Review of Brazilian and International Scientific Production}

Abstract

This integrative review aimed to investigate coping strategies at work, in order to broaden the understanding of the concept in the individualwork-organization relationship. The method adopted followed two main steps: 1) systematic literature search, analysis and selection of publications in Web of Science, Lilacs, Scielo, and Scopus databases, considering the entire period of publications, which totaled 592 articles; and 2) review of the 28 publications selected in the first stage. The inclusion criteria were investigations about coping at work and studies available for full reading. The results demonstrate that the promotion of educational actions for stress management and offering social support are essential to health in the organizational context. Interventions focused on the human being are also needed, as well as on the relationships between managers and other workers. In the organizational context, the findings point to the need for changes in physical and environmental conditions, aimed at promoting the quality of life, well-being and happiness of workers.

Keywords: professionals, workers, stress at work, coping strategies at work.

\section{Estrategias de Afrontamiento en el Contexto Laboral: una Revisión Integradora de la Producción Científica Brasileña e Internacional}

Resumen

Se trata de una revisión integradora que tuvo como objetivo investigar las estrategias de afrontamiento en el trabajo, con el fin de ampliar la comprensión del concepto en la relación individuo-trabajo-organización. El método adoptado siguió dos etapas principales: 1) búsqueda bibliográfica sistemática, análisis y selección de publicaciones en las bases de datos Web of Science, Lilacs, Scielo y Scopus, considerando todo el período de publicaciones, que totalizaron 592 artículos; y 2) revisión de las 28 publicaciones seleccionadas en la primera etapa. Los criterios de inclusión fueron investigaciones sobre afrontamiento en el trabajo y estudios disponibles para lectura completa. Los resultados demuestran que la promoción de acciones educativas para el manejo del estrés y la oferta de apoyo social son fundamentales para la salud en el contexto organizacional. También se necesitan intervenciones centradas en el individúo, así como en las relaciones entre gestores y trabajadores. En el contexto organizacional, los hallazgos apuntan la necesidad de cambios en las condiciones físicas y ambientales, buscando promover la calidad de vida, el bienestar y la felicidad de los trabajadores.

Palabras clave: profesionales, trabajadores, estrés en el trabajo, estrategias de afrontamiento en el trabajo. 
O contexto contemporâneo do trabalho caracteriza-se por transformações rápidas e importantes, tanto no que diz respeito às formas de produção, como em aspectos subjetivos, políticos e ideológicos que alteram significativamente os modos de vida dos trabalhadores (Zanelli, Borges-Andrade, \& Bastos, 2014). Se antes da situação crítica e de tensão proporcionada pela pandemia de COVID-19, já eram enfatizados os desafios relacionados ao trabalho, no momento atual isso fica ainda mais evidente, visto que as configurações de trabalho têm se tornado cada vez mais individualizadas e específicas. Ressalta-se que, do mesmo modo, que os trabalhadores foram lançados no trabalho remoto, os gestores e os outros trabalhadores passaram a enfrentar dificuldades decorrentes dos problemas econômicos advindos da pandemia (Cugnier \& Farsen, 2020). Junto a esse cenário, pesquisas que visam compreender comportamentos humanos nas organizações podem favorecer o bem-estar e a saúde aos indivíduos no ambiente de trabalho, a exemplo das estratégias de coping, tema central deste artigo.

Profissionais que atuam em diversas áreas e nas mais adversas condições de trabalho podem vivenciar situações como o estresse ocupacional e até mesmo a síndrome de burnout. O estresse ocupacional pode ser entendido como um conjunto de perturbações psicológicas ou sofrimento psíquico associado às experiências de trabalho. A síndrome de burnout, também conhecida como esgotamento profissional no Brasil, é uma resposta prolongada a estressores emocionais e interpessoais crônicos no trabalho, manifesta-se basicamente por sintomas de fadiga persistente, falta de energia, condutas como distanciamento afetivo, insensibilidade, indiferença ou irritabilidade relacionadas ao trabalho, além de sentimentos de ineficiência e baixa realização pessoal (Prado, 2016; Vieira, 2010).

Situações de estresse e outras demandas associadas ao trabalho frequentemente contribuem para o aumento do risco de desenvolver doenças (Rotenstein et al., 2016; Yates, Benson, Harris, \& Baron, 2012). O processo de estresse, além de desencadear prejuízos físicos e psicológicos, pode levar o indivíduo a desenvolver estratégias de enfrentamento, conhecidas na literatura como "estratégias de coping" (Maturana \& Valle, 2014). Atualmente, a definição mais utilizada em pesquisas sobre estratégias de enfrentamento é a de Lazarus e Folkman (1984), que definem estratégias de coping como uma variável individual representada pelas formas como as pessoas comumente reagem ao estresse, determinadas por fatores pessoais, exigências situacionais e recursos disponíveis.

Historicamente, pesquisadores têm se dedicado ao estudo sobre estratégias de coping, porém diferenças marcantes podem ser observadas em suas construções, tanto a nível teórico quanto a nível metodológico, decorrentes de suas raízes epistemológicas (Suls, David, \& Harvey, 1996).

Desde o início do século, pesquisas vinculadas à psicologia do ego vêm estudando o coping como mecanismos de defesa, motivados internamente e de forma inconsciente para lidar com conflitos sexuais e agressivos (Vaillant, 1994). Contudo, mais pesquisas foram desenvolvidas com o tempo e, a partir da década de 60 estendendo-se pelas duas décadas seguintes, outra geração de pesquisadores apontou uma nova perspectiva sobre este fenômeno, na qual enfatiza os comportamentos de coping e seus determinantes cognitivos e situacionais (Suls et al., 1996). Este período foi marcado por avanços na área e inúmeras publicações, em especial pelos pesquisadores Lazarus e Folkman.

A partir e uma compreensão cognitivista, Folkman e Lazarus (1985) apresentam estratégias de coping como um processo transacional entre a pessoa e o ambiente, com ênfase no processo tanto quanto em traços de personalidade. Os autores também propõem um modelo que divide as estratégias de coping em duas categorias: focalizado no problema e focalizado na emoção. Esta construção se baseou em análises que geraram dois fatores principais utilizados pelos pesquisadores para definir os dois tipos de estratégias de coping. Nesta perspectiva, estratégias de coping é definida como um conjunto de esforços, cognitivos e comportamentais, utilizado pelos indivíduos para lidar com demandas específicas, internas ou externas, que surgem em situações de estresse avaliadas como sobrecarga ou excedentes aos seus recursos pessoais (Lazarus \& Folkman, 1984).

O modelo de Folkman e Lazarus (1980) é conhecido como o modelo mais abrangente das proposições existentes e envolve quatro conceitos principais, os quais são: (a) coping é um processo ou uma interação que se dá entre o indivíduo e o ambiente; (b) sua função é a de administração da situação estressora; (c) os processos de coping pressupõem a noção de avaliação, ou seja, como o fenômeno é percebido, interpretado e representado cognitivamente pelo indivíduo; (d) o processo de coping se constitui em uma mobilização de esforço, pela qual os indivíduos irão empreender esforços cognitivos e comportamentais para administrar (reduzir, minimizar ou tolerar) as demandas internas ou externas que surgem da sua interação com o ambiente.

Folkman e Lazarus (1980) definem estratégias de coping como um mediador entre um evento estressor e o resultado advindo desse estressor. Este construto é objeto de estudo no campo da psicologia social, clínica e da personalidade, encontrando-se fortemente atrelado ao estudo das diferenças individuais (Antoniazzi, Dell'aglio, \& Bandeira, 1998). No contexto do trabalho, pesquisas sobre estratégias coping com trabalhadores de diversas categorias também tem sito desenvolvidas (Barros-Delben et al., 2019; Cancio et al., 2018; Casas, Repullo, \& Lorenzo, 2002; Koh et al., 2015; Lala et al., 2016; Loriol, 2016; Maran, Zedda, \& Varetto, 2018bem como estudos mais recentes envolvendo profissionais das áreas da saúde diante da pandemia de COVID-19 (Ho, Chee, \& Ho, 2020; Lai et al., 2020; Petzold, Plag, \& Ströhle, 2020).

A partir desse resgate histórico e conceitual, verificou-se que a concepção acerca das estratégias de coping se remodelou ao longo do tempo, partindo de um fenômeno individualizado, para avanços, por meio de pesquisas com foco nos profissionais e seus contextos de trabalho.

Ao se verificar o quanto o tema se consolidou nos últimos anos, e principalmente sua contemporaneidade, sobretudo no que diz respeito às mudanças no cotidiano do trabalho de diversas categorias profissionais após a pandemia do coronavírus, anunciada pela Organização Mundial da Saúde (OMS), em março de 2020 (Barros-Delben et al., 2020), se propôs por meio de uma revisão integrativa sobre o tema, investigar as estratégias de coping no ambiente de trabalho. O propósito maior é o de ampliar a compreensão do conceito na relação indivíduo-trabalho-organização. Espera-se, que os resultados desta investigação favoreçam aproximações e releituras entre a produção de conhecimento e o contexto de trabalho das organizações da atualidade.

\section{Método}

O método escolhido para este estudo é a revisão integrativa, considerada a categoria de revisão bibliográfica sistemática mais abrangente, pois utiliza literatura teórica ou empírica, qualitativa ou quantitativa, a depender do propósito da pesquisa. Em uma revisão integrativa, as literaturas podem ser focadas na metodologia, na teoria ou nos resultados de diferentes estudos empíricos, com um vasto rol de implicações (Botelho, Cunha, \& Macedo, 2011; Green et al., 2011).

O método de revisão integrativa proposto por Botelho et al. (2011) é composto por seis etapas: 1) Identificação do tema e seleção de pesquisa; 2) Estabelecimento de critérios de inclusão e 
exclusão; 3) Identificação dos estudos pré-selecionados e selecionados; 4) Categorização dos estudos selecionados; 5) Análise e interpretação dos resultados; e 6) Apresentação da revisão/síntese do conhecimento.

Esta revisão integrativa se constituiu a partir de uma busca sistemática nas bases de dados Web of Science, Lilacs, Scielo e Scopus, sendo que, o processo de desenvolvimento deste estudo ocorreu em duas etapas, apresentadas a seguir.

\section{Procedimento para Mapear os Estudos}

Realizamos buscas nas bases de dados Web of Science, Lilacs, Scielo e Scopus com os descritores (coping OR "coping behavior") AND (labor OR labour OR work OR job) AND (workers) AND (organizational OR organisational OR organization OR organisation).

$\mathrm{Na}$ base de dados Web of Science foram recuperados 483 resultados a partir do campo "tópicos", o que significa identificar os termos em títulos, resumos e palavras-chaves nos estudos. Em seguida, usamos os filtros "artigos" e "idiomas" (inglês, espanhol e português) para refinar os resultados, o que resultou em 83 estudos para análise preliminar, dos quais 27 foram selecionados para compor a revisão.

$\mathrm{Na}$ base Lilacs o resultado inicial foi de 113 estudos. O campo selecionado na busca foi "título", "resumo" e "assunto", além da seleção dos filtros "idioma" (inglês, espanhol e português) e "tipo de documento" (artigo). A base de dados Lilacs também oferece recurso para identificar o público alvo da pesquisa, o qual foi utilizado para encontrar estudos correspondentes à humanos, sexo feminino e/ou masculino e adultos. Com a seleção dos filtros, obteve-se 58 artigos, os quais foram analisados a partir de uma leitura preliminar e nenhum estudo foi selecionado por não apresentar relevância para nosso estudo.

$\mathrm{Na}$ Scopus foram recuperados 488 resultados no campo " $\mathrm{t}$ tulos, resumos e palavras-chaves" e, adotado procedimento para refinamento dos resultados iniciais "tipo de documento" (artigos e artigos de revisão) e idiomas (português, espanhol e inglês), 394 estudos foram considerados para a análise preliminar, dos quais 26 artigos foram identificados elegíveis para o estudo. Por fim, a pesquisa na base de dados Scielo resultou em 62 artigos, a partir do campo "todos os índices". Foram utilizados os filtros "tipo de literatura" (artigos) e "idiomas" (português, espanhol e inglês) e 57 artigos foram selecionados para a análise preliminar, contudo nenhum foi considerado elegível para a revisão.

A utilização de filtros teve o intuito de refinar os resultados das buscas e direcioná-las ao construto desejado. Os estudos pré-selecionados foram analisados a partir da leitura de título, resumo e palavras-chaves. Nesta análise preliminar também identificamos e excluímos duplicatas. Ressalta-se que consideramos todo o período de publicações (1980-2020) na busca sistemática, a fim de incluir os estudos mais relevantes sobre o tema. O procedimento descrito, o qual resultou em 28 publicações para compor o estudo, está representado por meio do fluxograma apresentado na Figura 1.

Consideramos elegíveis (a) estudos disponíveis para leitura na íntegra e (b) investigações acerca das estratégias de coping no trabalho.

\section{Revisão dos Estudos}

Após o levantamento descrito na etapa anterior, procedeu-se à análise das caraterísticas dos estudos e a revisão qualitativa dos mesmos.

\section{Resultados e Discussão}

Os resultados desta revisão integrativa serão apresentados em duas etapas: (1) caracterização dos estudos, conforme tabela 1, e (2) conceitos fundamentais sobre coping no ambiente de trabalho. A descrição qualitativa teve como base as categorias (1) significado de coping no trabalho; (2) recursos e estilos de coping e (3) níveis de análise e intervenção e pode ser considerado o estado da arte sobre o tema.

\section{Significado de Coping no Trabalho}

O estudo mais notável sobre coping é "Psychological stress and the coping process" de Richard Lazarus (1966), foi a partir deste estudo que o construto evoluiu como um campo de pesquisa em psicologia (Antoniazzi et al., 1998; Folkman \& Lazarus, 1980; Skinner, Edge, Altman, \& Sherwood, 2003). Estratégias de coping significa enfrentamento, é um processo psicológico usado para equilibrar recursos pessoais, demandas e necessidades individuais (Zhang, Wang, Millar, Lil, \& Yan, 2017). Diante de eventos estressores no trabalho, o indivíduo pode utilizar estratégias de coping, que corresponde à esforços cognitivos e comportamentais orientados para lidar com demandas internas e externas que estão excedendo ou sobrecarregando seus recursos individuais (Costa, Mombelli, Decesaro, Waidman, \& Marcon, 2011; Lazarus \& Folkman, 1987; 1984; Moreno, Gil, Haddad, \& Vannuchi, 2011).

Quando o indivíduo avalia uma situação de trabalho estressante, ele usará mecanismos de coping para controlar essa relação problemática entre ele e seu ambiente. O estresse é determinado por situações potencialmente estressantes ou fatores ambientais, juntamente com as características pessoais do indivíduo, o qual avalia a situação e os recursos disponíveis para enfrentá-la. A experiência subjetiva de estresse e, consequentemente, a implementação de mecanismos de coping dependerão do resultado dessa avaliação. Quando as estratégias de coping adotadas não forem ade-

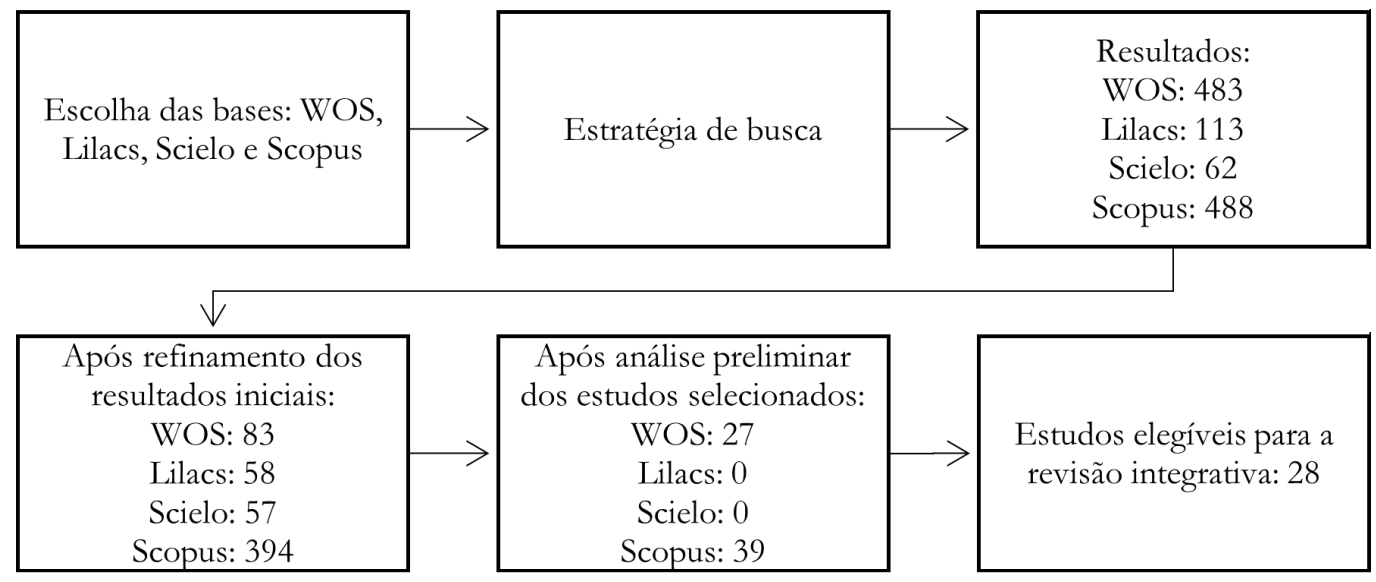

Figura 1. Fluxograma de busca sistemática de literatura. Fonte: Elaborado pelos autores (2020). 
Tabela 1

Características dos estudos da revisão integrativa

Autores $\quad$ Objetivo $c \begin{gathered}\text { Design e } \\ \text { público-alvo }\end{gathered}$

Analisar as experiências dos trabalhadores de proteção à criança com a violência do cliente, sua interpretação, suas

Lamothe et al. (2018) consequências percebidas e suas estratégias de enfrentamento.
Estudo qualitativo/

Trabalhadores de

proteção à criança $(n=30)$

Os trabalhadores reagem à violência do cliente de forma diferente, seja por envolvimento (ou seja, empatia) ou recuando com medo (ou seja, reagendando clientes, sendo severo)

- O estudo sugere duas maneiras pelas quais as organizações podem ajudar os trabalhadores a intervir para lidar com a violência do cliente e todas as suas complexidades: suporte proativo de colegas, supervisores e da organização, bem como treinamentos regulares.

\begin{tabular}{|c|c|c|}
\hline $\begin{array}{l}\text { Tohmiya et } \\
\text { al. (2018) }\end{array}$ & $\begin{array}{l}\text { Avaliar o estresse cognitivo entre os } \\
\text { trabalhadores e identificar fatores individuais } \\
\text { e ambientais relacionados }\end{array}$ & $\begin{array}{l}\text { Estudo transversal/ } \\
\text { Funcionários no } \\
\text { Japão }\end{array}$ \\
\hline $\begin{array}{l}\text { Maran et al. } \\
\text { (2018) }\end{array}$ & $\begin{array}{l}\text { Investigar os estressores operacionais e } \\
\text { organizacionais, suas consequências também } \\
\text { em termos de ansiedade e as estratégias de } \\
\text { enfrentamento adotadas }\end{array}$ & $\begin{array}{c}\text { Estudo transversal/ } \\
\text { Policiais }\end{array}$ \\
\hline $\begin{array}{l}\text { Akinsulure- } \\
\text { Smith et al. } \\
\text { (2018) }\end{array}$ & $\begin{array}{l}\text { 1) Examinar taxas de prevalência de saúde } \\
\text { mental deletéria e resultados ocupacionais, } \\
\text { como estresse traumático secundário e } \\
\text { burnout; 2) Explorar os mecanismos de } \\
\text { enfrentamento usados para gerenciar o } \\
\text { estresse relacionado ao trabalho e a influência } \\
\text { de tais estratégias e inteligência emocional no }\end{array}$ & $\begin{array}{l}\text { Estudo transversal/ } \\
\text { Trabalhadores } \\
(n=210) \text { de agências } \\
\text { de reassentamento } \\
\text { de refugiados nos } \\
\text { Estados Unidos }\end{array}$ \\
\hline
\end{tabular}

Uma estratégia eficaz para melhorar a saúde mental entre os trabalhadores

pode envolver uma abordagem interprofissional por enfermeiras de saúde

pública e profissionais de saúde, que inclui aprimorar habilidades de autocuidado, melhoria dos climas organizacionais nos locais de trabalho e apoio social comunitário.

- Os participantes lidaram com o estresse causado por estressores operacionais usando sua experiência e também adotando estratégias que poderiam ser úteis para diminuir a angústia percebida, tais como enfrentamento ativo, apoio e reinterpretação positiva da situação.

estresse traum

Duan-

Porter et al.

(2018)

Avaliar associações entre personalidade, coping, características do trabalho e burnou

Estudo transversal/

Trabalhadores de enfermagem de hospital privado $(n=281)$
- Estratégias de coping usadas são auto distração, humor, desabafo, uso de substâncias, desligamento comportamental e auto culpa.

- Necessidade de treinamento clínico e política organizacional com foco na saúde mental.

Intervenções devem considerar fatores profissionais e individuais.

- Os componentes potenciais incluem estratégias para gerenciar a afetividade negativa e reduzir o enfrentamento evitativo, como reenquadramento cognitivo e técnicas baseadas na atenção plena.

- Abordagens organizacionais para lidar com o esgotamento por meio do aumento de recursos no trabalho

- Estratégias de enfrentamento empregadas de saída, lealdade passiva e compromisso com os papéis e funções para lidar com as mudanças no trabalho.

Compreender como os trabalhadores da

Zhang et al. APS lidaram com o novo modelo de atenção

(2017) básica à saúde e as características profissionais decorrentes dessas mudanças.
Estudo qualitativo/ Trabalhadores da saúde na China atenção primária à

- Necessário que os formuladores de políticas forneçam mais recursos de

trabalho para os trabalhadores e envolvam os profissionais de saúde na formulação de políticas.

- Organização deve oferecer oportunidades de treinamento específicas para apoiar a orientação de funções de trabalho.
Explorar os efeitos do trabalho com crianças Método misto/ órfãs e vulneráveis nos trabalhadores de cuidados comunitários e estabelecer o impacto que a terapia do riso tem

Hatzipapas et al. (2017) para combater positivamente o estresse de trabalhar dentro do ambiente dos trabalhadores de cuidados

\begin{tabular}{|c|c|c|}
\hline $\begin{array}{l}\text { Andrade } \\
\text { \& Pérez- } \\
\text { Nebra } \\
(2017)\end{array}$ & $\begin{array}{l}\text { Investigar como o suporte social contribui } \\
\text { para as pessoas lidarem com situações } \\
\text { estressantes no ambiente de trabalho }\end{array}$ & $\begin{array}{l}\text { Método misto/ } \\
\text { Trabalhadores } \\
\text { voluntários }(n=51)\end{array}$ \\
\hline $\begin{array}{l}\text { Tummers } \\
\text { (2017) }\end{array}$ & $\begin{array}{l}\text { Analisar o efeito da estratégia de } \\
\text { enfrentamento no desempenho no trabalho, } \\
\text { conforme avaliado por seus supervisores }\end{array}$ & $\begin{array}{l}\text { Estudo transversal/ } \\
\text { Trabalhadores linha } \\
\text { de frente do serviço } \\
\text { público }\end{array}$ \\
\hline $\begin{array}{l}\text { Elliott et al. } \\
\qquad(2016)\end{array}$ & $\begin{array}{l}\text { Revisar o estresse e o enfrentamento dos } \\
\text { funcionários em resposta às altas demandas } \\
\text { de trabalho em organizações comunitárias } \\
\text { de tratamento de demência na Tasmânia, } \\
\text { Austrália }\end{array}$ & $\begin{array}{l}\text { Estudo transversal/ } \\
\text { Trabalhadores } \\
\text { de organizações } \\
\text { comunitárias na } \\
\text { Tasmânia, AU }\end{array}$ \\
\hline $\begin{array}{l}\text { Lala et al. } \\
\text { (2016) }\end{array}$ & $\begin{array}{c}\text { Analisar estratégias de enfrentamento e } \\
\text { fatores de estresse de risco e resiliência } \\
\text { em trabalhadores de unidades médicas de } \\
\text { emergência }\end{array}$ & $\begin{array}{l}\text { Estudo transversal/ } \\
\text { Equipe da Unidade } \\
\text { de Emergência na } \\
\text { França }(n=366)\end{array}$ \\
\hline
\end{tabular}

Estudo transversal/

Funcionários

públicos de uma

administração

governamental na

Alemanha $(n=948)$

Trabalhadores

voluntários que

trabalham com

famílias afetadas

elo HIV na África enfrentamento da exaustão psicológica al. (2016) de papéis, ambiguidade de papéis e
Mais emoções positivas, enfrentamento positivo, melhoria nas relaç̃
interpessoais e no trabalho após a exposição à terapia do riso.

- A terapia do riso como uma técnica de autocuidado tem potencial como uma estratégia de intervenção de baixo custo para reduzir o estresse e neutralizar

emoções negativas entre pessoas que trabalham em ambientes altamente emocionais.

- Investimentos em desenvolvimento de pessoas que estimulem a urbanidade nas organizações e criação de um espaço de escuta para colaboradores são sugestões de ações que podem beneficiar dimensões afetivas no trabalho.

- Estratégia de enfrentamento dos burocratas de rua está positivamente relacionado ao trabalho.

- Instituições para idosos que defendem o bem estar dos funcionários e apoiam os funcionários para lidar com suas funções de trabalho podem tem maior probabilidade de reter funcionários motivados e comprometidos.

- O uso de substâncias é um método de enfrentamento comum para médicos internos.

- A avaliação regular da percepção do pessoal sobre o estresse e os fatores relacionados ao estresse é essencial para apoiar as decisões organizacionais a fim de promover um melhor ambiente de trabalho e melhor atendimento ao paciente.

O enfrentamento focado no problema é crucial para manter a saúde mental ao lidar com expectativas contraditórias e pouco claras sobre o papel no trabalho.

- O enfrentamento focado na emoção parece sintomático em situações de trabalho psicologicamente disfuncionais que não podem ser tratadas de outra forma.

- As implicações são discutidas no contexto da crescente consciência das

demandas contraditórias que as organizações impõem aos funcionários. 
Tabela 1 (continuação)

Características dos estudos da revisão integrativa

\begin{tabular}{|c|c|c|c|}
\hline Autores & Objetivo & $\begin{array}{c}\text { Design e } \\
\text { público-alvo }\end{array}$ & Principais contribuições \\
\hline $\begin{array}{l}\text { Loriol } \\
(2016)\end{array}$ & $\begin{array}{l}\text { Analisar as experiências dos trabalhadores } \\
\text { de proteção à criança com a violência } \\
\text { do cliente, sua interpretação, suas } \\
\text { consequências percebidas e suas estratégias de } \\
\text { enfrentamento. }\end{array}$ & $\begin{array}{l}\text { Estudo qualitativo/ } \\
\text { Trabalhadores de } \\
\text { proteção à criança } \\
\qquad(n=30)\end{array}$ & $\begin{array}{l}\text { - As formas coletivas de enfrentamento fazem parte da mediação entre } \\
\text { potenciais estressores pela organização do trabalho e agravos à saúde. } \\
\text { - O estudo analisa o estresse como uma construção social e contribui para } \\
\text { uma melhor compreensão do significado do estresse em diferentes grupos } \\
\text { ocupacionais. }\end{array}$ \\
\hline
\end{tabular}

Investigar o impacto que o ambiente de trabalho em um hospital geral público local pode ter na saúde mental e emocional dos

Koinis et al. (2015) trabalhadores de saúde e encontrar estratégias para enfrentar as consequências negativas

Investigar os estressores operacionais e

Maran et organizacionais, suas consequências também

al. (2015) em termos de ansiedade e as estratégias de enfrentamento adotadas

Estudo transversal/

Profissionais de

saúde $(n=200)$ que

trabalhavam em um

hospital geral

Estudo transversal/

Policiais da Itália $(n=617)$

Estudo qualitativo/

Trabalhadores que

contribuem para

um grupo auto organizado do

Facebook

Richards Explorar as qualidades de enfrentamento auto
organizadas dos sites de redes sociais

Estudar a prevalência de burnout e morbidade psicológica entre os profissionais

Koh et al. de cuidados paliativos em Singapura e suas

(2015) associações com fatores demográficos e de local de trabalho, bem como o uso de mecanismos de enfrentamento

Estudo transversal

e multicêntrico/

Prestadores de

cuidados paliativos

do setor de

saúde pública em

Cingapura

Estudo transversal

e longitudinal/

Professores

universitários

não-efetivos de

universidades

públicas

Fatores significativos para reduzir o estresse no local de trabalho no sentido de

encorajar e recompensar moralmente os funcionários e também de fornecerlhes oportunidades de educação adicional ou contínua.

-Cursos de treinamento e apoio para lidar com o estresse ocupacional devem levar em consideração o gênero, a função e o tipo de trabalho.

- Cursos de treinamento personalizados e programas de apoio podem ser ferramentas úteis e eficazes para prevenir o estresse antes que se torne crônico.

- Os grupos organizados por funcionários no Facebook representam um importante desenvolvimento e extensão das práticas de enfrentamento disponíveis para indivíduos e grupos de trabalhadores. Deason organizacional, mecanismos comuns de (2014) enfrentamento e depressão, ansiedade e estresse entre os professores
Os resultados sugerem possibilidades de - Intervenção institucional atendendo às necessidades do corpo docente a fim de mitigar resultados negativos para instituições, alunos e professores. - Melhoria das condições de trabalho do corpo docente. estabelecimento de limites, transcendental (meditação e reflexão silenciosa), paixão pelo trabalho, expectativas realistas, lembrança de pacientes e atividades organizacionais foram associados a menos burnout.
Estudo transversal/

Trabalhadores $(n=$

323) de organizações comunitárias

Método misto/

Trabalhadores

voluntários $(n=51)$

\section{Gray-}

Muramatsu trabalho, recursos sociais e pessoais e burnout (2011)

Moreno et al. (2011)
Investigar como o suporte social contribui
para as pessoas lidarem com situações estressantes no ambiente de trabalho

- Os resultados ressaltam a importância de fortes redes de apoio social baseadas no trabalho e recursos de gerenciamento de estresse. 
Tabela 1 (continuação)

Características dos estudos da revisão integrativa

\begin{tabular}{|c|c|c|c|}
\hline Autores & Objetivo & $\begin{array}{l}\text { Design e } \\
\text { público-alvo }\end{array}$ & Principais contribuições \\
\hline $\begin{array}{l}\text { Riolli \& } \\
\text { Savicki } \\
(2003)\end{array}$ & $\begin{array}{l}\text { Analisar condições antecedentes de estresse } \\
\text { crônico, fatores de moderação pessoal de } \\
\text { otimismo / pessimismo e coping e o resultado } \\
\text { de burnout }\end{array}$ & $\begin{array}{l}\text { Estudo transversal/ } \\
\text { Trabalhadores } \\
\text { de serviços de } \\
\text { informação }(n=82)\end{array}$ & $\begin{array}{l}\text { - Otimismo e coping foram mais influentes sob alto estresse. } \\
\text { - O otimismo permite burnout relativamente baixo em todas as intensidades } \\
\text { de estresse, enquanto o coping pode realmente levar a um burnout menor } \\
\text { em situações altamente estressantes }\end{array}$ \\
\hline $\begin{array}{l}\text { Casas et al. } \\
\quad(2002)\end{array}$ & $\begin{array}{l}\text { Analisar o estresse relacionado ao trabalho no } \\
\text { setor saúde e os mecanismos de enfrentamento }\end{array}$ & Revisão bibliográfica & $\begin{array}{l}\text { - Sugere-se intervenções nos três níveis: individual - promover a capacidade } \\
\text { das pessoas de se adaptarem e enfrentarem o estresse produzido pela } \\
\text { organização; coletivo - criar mecanismos grupais de enfrentamento e } \\
\text { resolução de problemas; e organizacional - ações com base na melhoria da } \\
\text { qualidade de vida no trabalho. }\end{array}$ \\
\hline $\begin{array}{l}\text { Gates } \\
(2001)\end{array}$ & $\begin{array}{l}\text { Descrever um modelo para examinar o estresse } \\
\text { no local de trabalho e identificar estratégias para } \\
\text { avaliar e prevenir o estresse e a tensão }\end{array}$ & Estudo teórico & $\begin{array}{l}\text { - O modelo é direcionado a profissionais de saúde ocupacional - enfermeiros } \\
\text { do trabalho }\end{array}$ \\
\hline $\begin{array}{l}\text { Callaghan } \\
\text { et al. } \\
(2000)\end{array}$ & $\begin{array}{l}\text { Investigar fatores relacionados ao estresse e } \\
\text { enfrentamento entre enfermeiras chinesas em } \\
\text { Hong Kong }\end{array}$ & $\begin{array}{l}\text { Estudo transversal/ } \\
\text { Enfermeiras }\end{array}$ & $\begin{array}{c}\text { - Os entrevistados enfrentaram o estresse buscando apoio de amigos e } \\
\text { colegas, utilizando diferentes estratégias cognitivas e por meio de atividades } \\
\text { de lazer. }\end{array}$ \\
\hline
\end{tabular}

Nota. Fonte: Elaborado pelos autores (2020).

quadas, o indivíduo apresentará alterações fisiológicas e comportamentais que podem levar, caso persista a situação, a deterioração mais ou menos permanente da sua saúde (Casas et al., 2002; Peiró \& Salvador, 1993).

Existem duas abordagens tradicionais sobre estratégias de coping: (a) coping focado no problema e (b) coping focado na emoção. O coping focado no problema se refere a fazer algo para alterar a fonte do estresse para preveni-lo ou controlá-lo, enquanto o coping focado na emoção procura reduzir ou gerenciar o sofrimento emocional associado à situação (Lazarus \& Folkman, 1984; Zhang et al., 2017). A literatura também apresenta uma distinção entre estratégias de coping de controle e estratégias de coping de apoio, que compartilha semelhanças com as dimensões clássicas coping focado no problema e coping focado na emoção.

Coping de controle é uma abordagem focada no problema e visa exercer influência para lidar construtivamente com as causas de uma situação estressante. Isso implica em mudanças positivas no ambiente de trabalho ou a si mesmo para resolver as fontes de estresse. Coping de apoio são estratégias focadas na emoção, visam reduzir as consequências negativas de situações de trabalho estressantes buscando apoio social de outras pessoas, como supervisores, colegas, amigos ou familiares (Hornung, Lampert, \& Glaser, 2016; Zellars \& Perrewé, 2001). Connor-Smith e Flachsbart (2007) esclarecem que em comparação com o coping de controle, o coping de apoio, focado na emoção, tem uma conotação mais passiva e pode incluir elementos de desengajamento ou esquiva.

Estratégias de coping focadas no problema, como coping de controle, tendem a ser mais funcionais na manutenção da saúde mental do que as estratégias focadas na emoção. Isso porque, coping de controle implica em oportunidades para lidar construtivamente com uma situação estressante, enquanto coping de apoio pode ser um sintoma de exposição a estressores que não podem ser modificados, mas que precisam ser enfrentados (Connor-Smith \& Flachsbart, 2007).

Contudo, ressalta-se que, sob certas circunstâncias, buscar apoio emocional pode ser até disfuncional, exacerbando as tensões no trabalho, pois conversas sobre eventos negativos envolvem recordações e reforça as frustrações experimentadas e as respostas afetivas associadas aos eventos. O foco e a ventilação das emoçoes negativas podem aumentar o sofrimento e impedir o ajustamento ao distrair os indivíduos de tentar mudar a situação disfuncional relacionada ao trabalho (Fenlason \& Beehr, 1994; Zellars \& Perrewé, 2001).

As respostas de enfrentamento são baseadas em interações entre fatores individuais, situacionais e ambientais. O coping focado no problema é usado em situações suscetíveis a mudanças, é mais eficaz a longo prazo em protelar os efeitos do estresse, enquanto que o enfrentamento focado na emoção é escolhido quando estratégias mais ativas são avaliadas como ineficazes (Folkman \& Lazarus, 1980).

As estatégias de coping foram classificadas em oito categorias (Folkman \& Lazarus, 1980), significa que as pessoas usam diferentes estratégias de coping para gerenciar o estresse: confronto, afastamento, autocontrole, suporte social, aceitação, fuga-esquiva, resolução do problema e reavaliação positiva. Confronto inclui a visão de desafio e atenção para um aspecto da situação, envolvendo a avaliação das diversas possibilidades de ações e suas consequências. Afastamento correspondente às estratégias de negação de sentimento de medo ou ansiedade, onde o indivíduo tenta esquecer a verdade, recusando-se a acreditar que a situação esteja ocorrendo. Autocontrole é a tentativa de controlar a emoção advinda do problema. Suporte social ocorre quando o indivíduo recorre às pessoas do seu meio social na tentativa de obter apoio na resolução do seu problema (Folkman \& Lazarus, 1984; Lazarus \& Folkman, 1984).

A aceitação corresponde às estratégias utilizadas para aceitar a realidade da situação, acreditando na sua responsabilidade sobre ocorrido e que nada pode ser feito para mudar. Fuga-esquiva são as estratégias pelas quais o indivíduo tenta minimizar a gravidade da situação, recorrendo à fantasia, em substituição à percepção real do conflito. Na resolução do problema ocorre a elaboração de planos de ação e alternativas com o objetivo de resolução da situação. A reavaliação positiva é um mecanismo cognitivo para aceitação da realidade, onde o indivíduo tenta encontrar razões que amenizem a gravidade da situação ou concentra-se nos aspectos positivos da mesma, como forma de diminuir a carga emotiva do acontecimento, buscando alterar a situação (Folkman \& Lazarus, 1984; Lazarus \& Folkman, 1984).

Por fim, o modelo Exit/Voice/Loyalty/Neglect (EVLN) de Rusbult (1987) é uma das abordagens mais citadas na literatura sobre coping e apresenta quatro estilos básicos de enfrentamento: saída, voz, lealdade e negligência. Analisada no contexto do trabalho, se as pessoas estão insatisfeitas, elas podem se concentrar em seus interesses não relacionados ao trabalho e "negligenciar" sua situação de trabalho insatisfatória ou podem tentar melhorar a situação, através de "voz". Caso contrário, podem sair e encontrar um emprego melhor ("sair"). Por lealdade, podem ser motivadas e apoiar ativamente a organização ("lealdade ativa"); ou quando não estão motivados, podem ser silenciosos e pacientes, fazendo apenas o trabalho necessário ("lealdade passiva"). Esses estilos 
são descritos por duas dimensões primárias: ativo versus passivo, construtivo versus desconstrutivo.

\section{Recursos e Estilos de Coping}

A literatura também reconhece as estratégia de coping como recurso e estilo. Recursos são características pessoais (personalidade, crenças, lócus de controle, experiências traumáticas ou características genéticas) que levam à adoção de estratégias ativas ou passivas (Thoits, 2011). Estilo, por sua vez, diz respeito a modos habituais de lidar com o estresse (Carver, Scheier, \& Segerstrom, 2010), ou seja, é a tendência da pessoa para empregar mecanismos de superação das condições que excedem seus recursos pessoais adaptativos. Ressalta-se que, independentemente da perspectiva em que o coping é concebido, gera-se um impacto nas experiências estressantes.

Como já mencionado, a estratégia de coping adotada é precedida por uma avaliação cognitiva que o indivíduo faz diante do estresse percebido. Esta avaliação primária é dividida em ameaça e desafio, a ameaça descreve dano/perda antecipada e desafio descreve uma ameaça que pode ser atendida ou superada. Ressalta-se, ainda, que a avaliação de ameaça ou desafio pode afetar a saúde mental (Carpenter, 2016; Lazarus \& Folkman, 1984; Tohmiya, Tadaka, \& Arimoto, 2018).

A resposta e a estratégia de coping após a avaliação cognitiva diferem entre os indivíduos, mesmo em resposta aos mesmos estressores. Por exemplo, pessoas que fazem uma avaliação cognitiva positiva podem perceber o estresse como um problema de saúde desafiador a ser resolvido e estabelecerem metas desafiadoras. Por outro lado, aqueles que fazem uma avaliação cognitiva negativa podem ver o mesmo problema como uma ameaça à saúde e acreditam que a resolução do problema está além de suas habilidades (Lazarus \& Folkman, 1984; Tohmiya et al., 2018). A avaliação cognitiva positiva contribui para a qualidade de vida e para o bem estar do indivíduo; para as organizações é importante para controlar custos médicos ou afastamentos e aumento da produtividade organizacional.

O ambiente também pode condicionar os tipos de reações. Profissionais que tem oportunidades limitadas para influenciar as decisões, por causa de sua baixa posição na hierarquia, acabam por ter um lócus de controle externo, como estratégias de enfrentamento focadas na emoção ou na fuga. Da mesma forma, o ambiente pode favorecer a presença de recursos para implementar o enfrentamento baseado em ação. Nesse sentido, as organizações podem fornecer maiores ou menores recursos e meios para superar problemas (Loriol, 2016).

Estudo com enfermeiros destaca que os estilos de coping com as maiores médias de respostas são resolução de problema, suporte social e reavaliação positiva; e a menos utilizada fuga-esquiva (Rodrigues, 2006). Com psicólogos, as principais estratégias de coping foram prática de exercício físico, conversar com pessoas de confiança, ter vida social e senso de humor (Sanzovo \& Coelho, 2007).

Os estilos de coping podem variar entre sucesso e fracasso e os profissionais usam mecanismos diferentes para enfrentar uma condição estressante. Como sugerido por Carver et al. (2010), pessoas otimistas e pessimistas devem empregar espontaneamente mecanismos de avaliação e estratégias de coping bastante diferentes em face aos eventos estressantes.

Como já mencionamos, a experiência do estresse é subjetiva e mediada por variáveis pessoais que têm um papel determinante quando se trata de estabelecer os recursos físicos e psicológicos que o indivíduo pode usar para responder às demandas do ambiente de trabalho. As variáveis pessoais podem ser divididas em dois grandes grupos, os quais são fatores biológicos/demográficos e os fatores afetivos/cognitivos. Como fatores do primeiro grupo, tem-se a idade (indivíduos mais velhos têm mais conhecimento dos seus próprios recursos e mais experiência com uma variedade de situações, o que pode fornecer maior capacidade de resposta para enfrentar situações difíceis), sexo (neste caso, o estresse está mais ligado aos papeis sexuais que às diferenças biológicas, há maior nível de estresse em mulheres que aderiram ao mercado de trabalho e mantém a responsabilidade com suas famílias e tarefas domésticas), situação familiar, apoio social, ajuda real ou percebida pelo indivíduo em suas relações interpessoais tem influência importante sobre a saúde. Os fatores afetivos/cognitivos incluem padrão de conduta tipo A, lócus de controle, personalidade resistente, outras características que desempenham um papel importante no aparecimento de estresse são neuroticismo/ansiedade e a baixa tolerância à ambigüidade (Casas et al., 2002). Nesse sentido, estratégias para lidar com o estresse no âmbito do trabalho devem levar em consideração o gênero, a função e o tipo de trabalho, cursos de treinamento e programas de apoio personalizados podem ser ferramentas úteis e eficazes para prevenir o estresse antes que se torne crônico (Maran, Varetto, Zedda, \& Ieraci, 2015).

Os estilos de coping podem ser adaptativos, reduzindo o estresse e promovendo bem estar e saúde a longo prazo (coping positivo), ou mal adaptativos, que pode reduzir o estresse a curto prazo, mas trazem consequências sérias a longo prazo (coping negativo). Diante dos desafios em seu ambiente de trabalho, as pessoas adotam estilos de coping positivos ou negativos. Dentre as estratégias positivas de coping, destaca-se o apoio social. Falar sobre frustrações e medos como uma maneira de lidar com estressores diários ajuda a superar os sentimentos de sobrecarga pelos problemas e limitações de seu ambiente de trabalho (Andrade \& Pérez-Nebra, 2017; Callaghan, Tak-Ying, \& Wyatt, 2000; Gates, 2001; Hatzipapas, Visser, \& Rensburg 2017; Lamothe et al. 2018). Apoio social, ou suporte social, pode ser de forma objetiva e subjetiva, como postularam Lazarus e Folkman (1984), e se fundamenta na crença de que o indivíduo é valorizado, estimado e amado pelo outro, sua oferta provém de diversas fontes como gestores, colegas de trabalho, familiares e amigos e pode ser do tipo emocional, instrumental e informacional (Steg \& Rothengatter, 2017).

O suporte emocional é o mais típico entre os três, adotado em estudos sobre suporte social (Lazarus \& Folkman, 1987; Steg \& Rothengatter, 2017; Taylor, 2010) e envolve tranquilizar o outro, demonstrando sua importância. O suporte instrumental se refere à prestação de assistência tangível, como apoio financeiro ou outras formas de auxílio específico. O suporte informacional ocorre quando uma pessoa ajuda a outra a entender melhor as condições estressantes e a escolher recursos adequados para enfrentá-las (Andrade \& Pérez-Nebra, 2017).

Stroebe e Stroebe (1996) apontam que a probabilidade de receber ajuda está mais relacionada com a intensidade das relações do que com o número de pessoas constantes na rede social. A busca por suporte social pode ser benéfica e útil para desabafar, aliviar tensão, sentir-se mais bem-humorado, concentrar-se melhor, manter-se descontraído e seguro (Calvetti, 2017; Taylor, 2010). Para a saúde mental, isso significa que o suporte social ajuda na prevenção de depressão, ansiedade e outros problemas de natureza psicológica, incluindo àquelas relacionadas ao trabalho.

Estratégias ligadas a religião, orações e atividades religiosas em geral em tempos de estresse traz alívio emocional e apoio por meio de tais atividades. No que diz respeito a importância da espiritualidade no enfrentamento do estresse, as crenças espirituais podem ajudar a lidar com situações de estresse e orientar o indivíduo internamente a acreditar em um senso de missão pessoal e 
realização (Hatzipapas et al., 2017). Koh et al. (2015) descobriram que a espiritualidade era um importante protetor contra o burnout, os autores também levantaram as estratégias positivas de enfrentamento utilizadas por enfermeiras chinesas, as quais estavam ligadas a espriritualidade.

Atividades de relaxamento como leituras, exercícios físicos, práticas envolvendo a criatividade e música permitem processar as circunstâncias de trabalho, trazendo sensação de rejuvenescimento através dos vários tipos de atividades de relaxamento (Hatzipapas et al., 2017). Estudo desenvolvido com enfermeiras chinesas, recentemente mencionado, mostrou que estratégias como apoio de pessoas, processos cognitivos, atividades de lazer, descanso e sono, relaxamento e a espiritualidade foram destacadas por este grupo de profissionais (Koh et al., 2015).

Outros mecanismos positivos de coping envolvem estratégias coletivas como o uso de redes sociais virtuais como um espaço para lidar de forma coletiva com problemas relacionados ao trabalho (Cohen \& Richardson, 2015). O Facebook, por exemplo, é um recurso importante para o desenvolvimento e extensão das práticas de coping disponíveis para indivíduos e grupos de funcionários, Korczynski (2003) considera tais práticas como novas e emergentes formas para criar e sustentar "comunidades de enfrentamento". No ambiente de trabalho, as pessoas podem usar recursos organizacionais para lidarem com o estresse, por exemplo, contar com o apoio de seus supervisores e colegas (suporte social) (Andrade \& Pérez-Nebra, 2017; Lamothe et al., 2018), propostas e alternativas de enfrentamento positivo, a nível da organização, trataremos mais adiante.

As pessoas também podem lidar de forma positiva com o estresse encontrando significado e propósito no trabalho, reconhecendo suas limitações (autoconsciência), mantendo expectativas realistas e aprendendo a estabelecer limites aos outros (pares, supervisores e clientes). É essencial sentir confinça nos colegas de trabalho para suporte emocional, resolução de problemas, recuperando sua objetividade (reestruturação cognitiva) ou simplesmente ter alguém que lhes substitua enquanto faz um intervalo (isso envolve saber onde está o limite) (Lamothe et al., 2018).

Sanzovo e Coelho (2007) dividem estilos positivos de coping em quatro categorias: a categoria A engloba aspectos fisiológicos, como a prática de exercícios físicos e relaxamento; a categoria B é o sistema de apoio, envolve estratégias como conversas com pessoas de confiança e orações; na categoria C se encontram o trabalho voluntário, atividades de recreação e lazer e hobbies, passar tempo com a família e ter hábito de leitura; e a categoria D são as habilidades interpessoais e de controle, senso de humor, estudar e pesquisar e ser uma pessoa otimista.

Destaca-se a importância das emoções positivas no processo de coping. As emoções positivas associadas ao otimismo permitem que o indivíduo persista diante das dificuldades, facilita a recuperação de danos ou perdas e restaura seus recursos naturais, sobretudo em situações altamente estressantes. Otimismo e estratrégias de coping estão ligados a baixos escores de burnout em todas as intensidades de estresse (Riolli \& Savicki, 2003).

Contudo, às vezes as estratégias de coping não são adaptativas (coping negativo). Coping negativo é o uso de estratégias ineficazes como, por exemplo, minimizar a gravidade do estresse vivenciado e tentar ignorar ou mesmo negar as consequências de tais experiências (Lamothe et al., 2018). Outras estratégias identificadas são de natureza compensatórias, como trabalhar horas extras não remuneradas, não fazer descanso no intervalo, reduzir as expectativas em relação aos resultados (alcançar menos resultados) e evitar responsabilidades ao tentar lidar com o estresse no trabalho (Astvik, Melin, \& Allvin, 2014).

Profissionais que tendem a usar estratégias de evitação ou ne- gação dos problemas que estão presentes no trabalho, têm níveis mais elevados de estresse. A negação ou a evitação reduz sintomas de estresse, mas não altera os fatores que são a causa deles, permite melhor funcionamento psicológico e possui grande importância adaptativa a curto prazo. No entanto, a negação pode gerar mais estresse porque os problemas não são resolvidos, o que pode levar a uma reação em espiral (Guic, Mora, Rey, \& Robles, 2006).

Estratégias negativas de coping também incluem a supressão de emoções e autonegligência. Em determinados contextos de trabalho, profissionais tendem a deixar seus sentimentos de lado para que possam trabalhar efetivamente com seu público e lidar com situações de estresse. No entanto, a supressão de sentimentos tem um impacto negativo em seu bem estar emocional. No que diz respeito a autonegligência, a longo prazo, a falta de autocuidado e apoio emocional resultam em sentimentos de incompetência (Hatzipapas et al., 2017). Logo, o uso de estratégias positivas voltadas para buscar informações, pedir ajuda e promover mudanças tem efeito positivo na redução do estresse e contribui com resultados para as organizações.

\section{Níveis de Análise e de Intervenção: Individual, Grupal e Organizacional}

Para abordar adequadamente o problema do estresse no ambiente de trabalho, é importante avaliar não apenas fatores organizacionais, mas também pessoais, uma vez que, como vimos até aqui, fatores individuais são variáveis mediadoras do estresse. Sendo assim, levando em consideração o nível de análise e intervenção, as estratégias de coping podem ser classificadas em estratégias individuais e estratégias organizacionais e de grupo.

Dentre as estratégias individuais voltadas ao controle do estresse, Casas et al. (2002) destacaram ainda dois grandes grupos: atividades voltadas para a aquisição de estratégias paliativas e aquelas voltadas para a aquisição de estratégias instrumentais. Embora na prática seja difícil separar pensamentos, sentimentos e comportamentos, uma vez que são efeitos interdependentes e recíprocos, cada um desses grupos pretende atuar sobre os aspectos mencionados através de diferentes tipos de abordagem terapêutica. As atividades voltadas à aquisição de estratégias de natureza paliativa, visando à aquisição de habilidades para gerenciar emoções, enfatizam o treinamento em relaxamento e outras técnicas como biofeedback, meditação, treinamento físico, etc. Atividades para a aquisição de estratégias instrumentais, modificam processos cognitivos, através de técnicas cognitivas e de autocontrole que eliminam padrões desadaptativos e estratégias que visam adquirir novas habilidades comportamentais (Akinsulure-Smith, Espinosa, Chu, \& Hallock, 2018; Casas et al., 2002; Duan-Porter et al., 2018).

Contudo, intervenções baseadas apenas em aspectos pessoais não permitem a redução significativa dos níveis de estresse ou oferecem subsídios para a adoção de estratégias de enfrentamento eficazes (Akinsulure-Smith et al., 2018). Nesse sentido, diante às demandas apresentadas no ambiente de trabalho, as organizações podem contribuir para que os trabalhadores tenham estratégias de coping positivas.

Segundo Zhang et al. (2017) algumas demandas de trabalho consideradas estressantes são a combinação de novas funções, mudança organizacional, alterações nos quadros funcionais e funções, bem como a saúde financeira da organização e situação econômica do mercado. Diante dessas condiçoes, ações ou programas com foco na oferta de suporte social, por meio de gestores e colegas, são recursos que promovem o bem estar dos profissionais (Lamothe et al., 2018). No âmbito do trabalho, o suporte social se fundamenta na crença de que o indivíduo é valorizado, estimado e cuidado pela organização (Siqueira, 2005). Ações desta natureza 
podem ser desenvolvidas a custos reduzidos, o que torna a proposta interessante e alinhada à prática organizacional.

Além disso, treinamentos sobre gerenciamento de estresse podem ajudar os profissionais a desenvolverem gradualmente crenças de controle interno mais fortes e adotar comportamentos de enfrentamentos ativos, assim como sessões de terapia por meio de programa de assistência aos empregados. Intervenções específicas podem facilitar a distinção entre os tipos de situações que podem ou não ser controladas e desenvolver habilidades de coping no trabalho (Gray-Stanley \& Muramatsu, 2011).

As estratégias de coping variam de acordo com o objetivo desejado. De modo geral, intervenções devem incluir ações focadas no indivíduo, baseadas em habilidades comportamentais, cognitivas, técnicas baseadas na atenção plena, educação em saúde e atividades físicas; focadas nas relações de trabalho, que compreende ações para melhoria da comunicação e trabalho em equipe, entre outras; e foco na organização, com a mudança das condições físicas e ambientais. Ressalta-se que intervenções combinadas, que associam dois ou mais tipos de intervenções com focos distintos, são as mais adequadas (Duan-Porter et al., 2018; Moreno et al., 2011), levando em conta que principais motivos para o desenvolvimento da Síndrome de Burnout estão vinculados a problemas relacionais e organizacionais (Trindade, Lautert, Beck, Amestoy, \& Pires, 2010). Benevides (2002) sugere ainda intervenção em todos os níveis: centrados na resposta do indivíduo (individual), no contexto ocupacional (organizacional) e na interação contexto ocupacional e indivíduo (combinadas).

Como visto, as estratégias de coping podem ser destinadas a resolver o problema (alterando a situação ou a percepção do indivíduo) ou se concentrando nas respostas emocionais do indivíduo. Este último seria apropriado quando não é possível ter o controle sobre a situação e, embora nossa sociedade valorize o domínio e a posse de mecanismos destinados a resolver o problema, nesses casos o enfrentamento efetivo incluirá tudo o que permitir que o indivíduo tolere, minimize, aceite ou até mesmo ignore o que não pode dominar (Lazarus, 1988). No ambiente de trabalho, consideramos o fato de que o controle da situação muitas vezes não está nas mãos do indivíduo, assim, as respostas ao estresse no local de trabalho exigem o envolvimento ativo de toda a organização, propondo mudanças na estrutura organizacional, redesenhando posições, desenvolvendo sistemas de promoção apropriados, etc, embora também seja benéfico trabalhar em nível individual (Casas et al., 2002; Reevy \& Deason, 2014).

As estratégias organizacionais com foco na promoção do bem estar dos funcionários e apoio para que possam lidar com suas funções de trabalho também tem maior probabilidade de reter funcionários motivados e comprometidos (Elliott, Stirling, Martin, Robinson, \& Scott, 2016). Parkes (2001) enfatiza que é ingênuo e até mesmo questionável que profissionais sejam submetidos a programas de treinamento sobre estresse, enquanto que as demandas excessivas ou condições inadequadas permanecem na empresa. Peiró e Salvador (1993) estabeleceram áreas de melhoria no que diz respeito as estratégias de grupo e organizacionais: condições ambientais, flexibilidade de horários, enriquecimentos dos postos de trabalho, estrutura organizacional, planos de carreira e incentivos, estilos de liderança e grupos semi autônomos de trabalho. Ações significativas para reduzir o estresse no local de trabalho devem ser pensadas, principamente no sentido de encorajar e recompensar moralmente os funcionários e também de fornecer-lhes oportunidades de educação adicional ou contínua (Koinis et al., 2015).

O trabalho está associado a situações de estresse dos trabalhadores principalmente porque as organizações são responsáveis pelas condições relacionadas ao ambiente de trabalho, clima or- ganizacional, design de empregos, relações interpessoais estabelecidas etc, aspectos que o trabalhador tem pouco ou nenhum controle. O enfrentamento positivo do estresse está relacionado a bons resultados no trabalho (Tummers, 2017) e intervenções que possam promover saúde, qualidade de vida e bem estar que visam motivar e energizar os funcionários a enfrentarem os desafios de suas práticas, são ações eficazes para a manutenção da saúde, prevenção de doenças e para o desempenho no trabalho.

\section{Considerações Finais}

Este artigo apresentou uma análise das produções científicas sobre as estratégias de coping no ambiente de trabalho. Para facilitar a compreensão sobre o construto, este estudo iniciou com um breve resgate histórico e conceitual acerca da concepção de coping no ambiente de trabalho, onde vimos que o conceito se remodelou ao longo do tempo partindo de um fenômeno individualizado, houve também avanços no que diz respeito às pesquisas envolvendo profissionais e seus contextos de trabalho.

Tendo como base os estudos analisados na revisão integrativa, compreendemos que situações de estresse e outras demandas associadas ao trabalho frequentemente contribuem para o aumento do risco de desenvolver doenças. Diante de situações ameaçadoras, os profissionais usam diferentes estratégias para se adaptar e lidar com a realidade do seu trabalho.

Estratégias de enfrentamento (coping) são respostas ao estresse e correspondem aos esforços cognitivos e comportamentais orientados para lidar com as demandas internas ou externas, que estão excedendo ou sobrecarregando os recursos do indivíduo. Algumas estratégias de coping podem ser úteis e fortalecedoras ( $\mathrm{CO}^{-}$ ping positivo), como suporte social, atividades religiosas e de relaxamento como leituras, exercícios físicos e práticas envolvento música, criatividade, entre outras. Mas, outras podem ser equivocadas e prejudiciais (coping negativo), neste grupo estão estratégias de evitação ou negação dos problemas, supressão de emoções e auto negligência.

As organizações podem promover ações educativas para gerenciamento de estresse, oferta de suporte social e mudanças na estrutura como um todo, embora também seja benéfico trabalhar em nível individual. Nesse sentido, para que as organizações possam desenvolver e fortalecer estratégias de coping eficazes, são necessárias intervenções focadas no indivíduo, nas relações da pessoa com o trabalho e na organização, este último com a mudança das condições físicas e ambientais para a promoção de saúde e bem estar dos profissionais.

Como limitação do estudo, destaca-se o fato de não ter sido incluído a base PsycINFO, assim como não ter sido considerado a Biblioteca Virtual em saúde (BVS), ao invés da LILACS, uma vez que todo material indexado na LILACS está indexado na BVS, podendo ser recuperado estudos importantes sobre o tema.

Contudo, estima-se que o objetivo inicialmente proposto para este trabalho foi alcançado. Uma vez que, os resultados encontrados são considerados relevantes para orientar pesquisas futuras, principalmente, as que se encontram relacionadas ao coping na área de Psicologia Organizacional e do Trabalho. Isto porque, nos estudos que versam sobre coping, são demonstradas relações com o estresse ocupacional, burnout e desempenho no trabalho. Nesse sentido, pesquisas futuras poderão explorar a relação entre coping e outros elementos presentes nas organizações, tais como desempenho organizacional e demais aspectos do contexto laboral. O que, por conseguinte, nos leva a compressão, de que, compreender tais relações, se torna relevante e inovador, tanto do ponto de vista teórico, quanto de intervenção nas organizações. 


\section{Referências}

Akinsulure-Smith, A. M., Espinosa, A., Chu, T., \& Hallock, R. (2018). Secondary traumatic stress and burnout among refugee resettlement workers: The role of and emotional intelligence. Journal of Traumatic Stress, 31(2), 202-212. https://doi.org/10.1002/jts.22279

Andrade, V. L. P., \& Pérez-Nebra, A. R. (2017). Suporte Social e Estresse no Trabalho: uma Análise com Métodos Mistos. Contabilidade, Gestão e Governanca (Brasilia), 20(3), 442-462. https://doi.org/10.21714/1984$39252017 \mathrm{v} 20 \mathrm{n} 3 \mathrm{a} 7$

Antoniazzi, A. S., Dell'aglio, D. D., \& Bandeira, D. R. (1998). O conceito de coping: uma revisão teórica. Estudos de Psicologia (Natal), 3(2), 273-294. https://doi.org/10.1590/\$1413-294X1998000200006

Astvik, W., Melin, M., \& Allvin, M. (2014). Survival strategies in social work: A study of how coping strategies affect service quality, professionalism and employee health. Nordic Social Work Research, 4(1), 52-66. https://doi. org/10.1080/2156857X.2013.801879

Barros-Delben, P., Cruz, R. M., de Melo, H. M., Teixeira, M. L., de Mendonça, S A., Pereira, G. K., \& Thieme, A. L. (2019). Coping e padrões biológicos de sono em expedicionários antárticos. Revista Psicologia em Pesquisa, 13(2), 145 166. https://doi.org/10.34019/1982-1247.2019.v13.26780

Barros-Delben, P., Cruz, R. M., Trevisan, K. R. R., Gai, M. J. P., Carvalho, R. V. C., Carlotto, P. A. C., . . \& \& Malloy-Diniz, L. F. (2020). Saúde mental em situação de emergência: COVID-19. Revista debates in psychiatry, 10(2), 18-28. Recuperado de https://d494f813-3c95-463a-898c-ea1519530871. filesusr. com/ugd/c37608 e2757d5503104506b30e50caa6fa6aa7.pdf

Benevides, P. A. M. T. (2002). Burnout: o processo de adoecer pelo trabalho. Em P. A. M. T. Benevides, Burnout: quando o trabalho ameaça o bem-estar do trabalhador. São Paulo: Editora Casa do Psicólogo.

Botelho, L. L. R., Cunha, C. C. A., \& Macedo, M. (2011). O método da revisão integrativa nos estudos organizacionais. Revista Eletrônica Gestão e Sociedade, 5(11), 121-136. https://doi.org/10.21171/ges.v5i11.1220

Calvetti, P. Ü. (2017). Níveis de ansiedade, estresse percebido e suporte social em pessoas que vivem com HIV/Aids. Psicologia: Teoria e Pesquisa, 32(4). https:// doi.org/10.1590/0102.3772e324317

Callaghan, P., Tak-Ying, S. A., \& Wyatt, P. A. (2000). Factors related to stress and coping among Chinese nurses in Hong Kong. Journal of advanced nursing, 31(6), 1518-1527. Recuperado de https://onlinelibrary.wiley.com/doi/ abs/10.1046/j.1365-2648.2000.01434.x

Cancio, E. J., Larsen, R., Mathur, S. R., Estes, M. B., Johns, B., \& Chang, M. (2018). Special Education Teacher Stress: Coping Strategies. Education and Treatment of Children, 41(4), 457-481. https://doi.org/10.1353/etc.2018.0025

Carpenter, R. (2016). A review of instruments on cognitive appraisal of stress. Arch Psychiatr Nurs, 30, 271-279. https://doi.org/10.1016/ j.apnu.2015.07.002

Carver, C. S., Scheier, M. F., \& Segerstrom, S. C. (2010). Optimism. Clinical Psychology Review, 30, 879-889. https://doi.org/10.1016/ j.cpr.2010.01.006

Casas, J., Repullo, J. R. \& Lorenzo, S. (2002). Estrés laboral en el medio sanitario y estrategias adaptativas de afrontamiento. Rev Calidad Asistencial, 17(4), 23746. https://doi.org/10.1016/S1134-282X(02)77511-8

Cohen, N., \& Richardson, J. (2015). 'I didn't feel like I was alone anymore’: evaluating self-organised employee coping practices conducted via Facebook. New Technology, Work and Employment, 30(3), 222-236. https://doi. org/10.1111/ntwe.12051

Costa, J. B., Mombelli, M. A., Decesaro, M. N., Waidman, M. A. P., \& Marcon, S S. (2011). Estrés y recursos de enfrentamiento del cuidador en el contexto hospitalário. Salud Mental, 34, 129-138. Recuperado de http://www.scielo. org.mx/scielo.php?script $=$ sci arttext\&pid $=$ S0185-33252011000200006

Connor-Smith, J. K.; \& Flachsbart, C. (2007). Relations between personality and coping: A meta-analysis. Journal of Personality \& Social Psychology, 93, 10801107. https://doi.org/10.1037/0022-3514.93.6.1080

Cugnier, J. S., \& Farsen, T. C. (2020). Construção de organizações saudáveis e resilientes. Em N. Silva \& L. P. Damo (Ed.) Vidas que mudaram: contribuiçoes da psicologia positiva para situacões de isolamento e de distanciamento social (pp. 119128). Florianópolis: Editora da UFSC.

Cummings, C., Singer, J., Moody, S. A., \& Benuto, L. T. (2020). Coping and workrelated stress reactions in protective services workers. The British Journal of Social Work, 50(1), 62-80. https://doi.org/10.1093/bjsw/bcz082

Duan-Porter, W., Hatch, D., Pendergast, J. F., Freude, G., Rose, U., Burr, H., ... \& Potter, G. (2018). 12-month trajectories of depressive symptoms among nurses - Contribution of personality, job characteristics, coping, and burnout. Journal of Affective Disorders, 234, 67-73. https://doi.org/10.1016/j. 这.2018.02.090

Elliott, K. E. J., Stirling, C. M., Martin, A. J., Robinson, A. L., \& Scott, J. L. (2016). We are not all coping: A cross-sectional investigation of resilience in the dementia care workforce. Health Expectations, 19(6), 1251-1264. https://doi. org $/ 10.1111 /$ hex.12419

Fenlason, K., \& Beehr, T. (1994). Social support and occupational stress: Effects of talking to others. Journal of Organizational Behavior, 15, 157-175. https:// doi.org/10.1002/job.4030150205
Folkman, S., \& Lazarus, R. S. (1980). An analysis of coping in a middle-aged community sample. Journal of Health and Social Behavior, 21, 219-239. https:// doi.org $/ 10.2307 / 2136617$

Folkman, S., \& Lazarus, R. S. (1985). If it changes it must be a process: A study of emotion and coping during three stages of a college examination. Journal of Personality and Social Psychology, 48, 150-170. https://doi. org/10.1037//0022-3514.48.1.150

Folkman, S., \& Lazarus, R. S. (1984). Personal control and stress and coping processes. A theoretical analysis. Journal Pers Soc Psychol, 46, 839-2. https:// doi.org/10.1037/0022-3514.46.4.839

Gates, O. M. (2001). Stress and Coping A Model for the Workplace. AAOHN Journal, 49(8), 390-398. https://doi.org/10.1177/216507990104900805

Gilstrap, C. M., Schall, S., \& Gilstrap, C. A. (2019). Stress in international work: Stressors and coping strategies of RNGO international directors. Communication Quarterly, 67(5), 506-525. https://doi.org/10.1080/01463373 .2019 .1668441

Gray-Stanley, J. A., \& Muramatsu, N. (2011). Work stress, burnout, and social and personal resources among direct care worker. Research in Developmental Disabilities, 32, 1065-1074. https://doi.org/doi: 10.1016/j.ridd.2011.01.025

Green, S., Higgins, J. P. T., Alderson, P., Clarke, M. Mulrow, C. D., \& Oxman, A. D. (2011), Chapter 1: Introduction. Em J. P. T. Higgins \& S. Green (Eds.), Cocbrane bandbook for systematic reviews of interventions. The Cochrane Collaboration: London.

Guic, E. S., Mora, P., Rey, R., \& Robles, A. (2006). Estrés organizacional y salud en funcionários de centros de atención primaria de una comuna de Santiago. Rev Méd Chile, 134, 447-455. https://doi.org/10.4067/S0034$\underline{98872006000400007}$

Hatzipapas, I., Visser, M., \& Rensburg, E. J. (2017). Laughter therapy as an intervention to promote psychological well-being of volunteer community care workers working with HIV-affected families. Journal of Social Aspects of HIV/AIDS, 14(1). https://doi.org/10.1080/17290376.2017.1402696

Ho, C. S., Chee, C. Y., \& Ho, R. C. (2020). Mental health strategies to combat the psychological impact of COVID-19 beyond paranoia and panic. Ann Acad Med Singapore, 49(1), 1-3. Recuperado de https://www.annals.edu.sg/ pdf/49VolNo3Mar2020/V49N3p155.pdf

Hornung, S., Lampert, B., \& Glaser, J. (2016). Dealing with Organizational Double Binds: Three-way Interactive Effects of Role Stressors and Coping on Worker Exhaustion. Psychological Reports, 118(2), 487-509. https://doi. org/10.1177/0033294116637732

Koh, M. Y. H., Chong, P. H., Neo, P. S. H., Ong, Y. J., Yong, W. C., Ong, W.Y., Shen, M. L. J., \& Hum, A.Y. M. (2015). Burnout, psychological morbidity and use of coping mechanisms among palliative care practitioners: A multientre cross-sectional study. Palliative Medicine, 29(7), 633-642. https://doi. org $/ 10.1177 / 0269216315575850$

Koinis, A., Giannou, V., Drantaki, V., Angelaina, S., Stratou, E., \& Saridi, M. (2015). The impact of healthcare workers job environment on their mentalemotional health. Coping strategies: the case of a local general hospital. Health psychology research, 3(1). https://doi.org/10.4081/hpr.2015.1984

Lai, J., Ma, S., Wang, Y., Cai, Z., Hu, J., Wei, N., ... \& Hu, S. (2020). Factors associated with mental health outcomes among health care workers exposed to coronavirus disease 2019. JAMA network open, 3(3), e203976-e203976. https://doi.org/10.1001/jamanetworkopen.2020.3976

Lala, A. I., Sturzu, L. M., Picard, J. P., Druot, F., Grama, F., \& Bobirnac, G. (2016). Coping behavior and risk and resilience stress factors in French regional emergency medicine unit workers: a cross-sectional survey. Journal of medicine and life, 9(4), 363-368. Recuperado de https://www.ncbi.nlm.nih. gov/pmc/articles/PMC5141395/pdf/JMedLife-09-363.pdf

Lamothe, J., Couvrette, A., Lebrun, G., Yale-Soulière, G., Roy, C., Guay, S., \& Geoffrion, S. (2018). Violence against child protection workers: A study of workers' experiences, attributions, and coping strategies. Child Abuse \& Neglect, 81, 308-321. https://doi.org/10.1016/i.chiabu.2018.04.027

Lazarus, R. S. (1988). Vulnerabilidad y resistencia individuales al estrés psíquico. Em R. Kalimo, M. A. El-Batawi, \& C. L. Cooper (Orgs.), Los factores psicosociales en el trabajo (pp. 125-131). Genebra: OMS.

Lazarus, R. S., \& Folkman, S. (1987). Transactional theory and research on emotions and coping. European Journal of Personality, 1(3), 141-169. https:// doi.org/10.1002/per.2410010304

Lazarus, R.S., \& Folkman, S. (1984). Stress, appraisal and coping. New York: Springer. https://doi.org/10.1007/978-1-4419-1005-9 215

Lipp, M. E. N., \& Malagris, L. E. N. (2001). O stress emocional e seu tratamento. Em B. Rangé (Org), Psicoterapias cognitivo-comportamentais: um diálogo com a psiquiatria (pp. 475-490). Porto Alegre: Artmed.

Loriol, M. (2016). Collective forms of coping and the social construction of work stress among industrial workers and police officers in France. Theory and Psychology, 26(1) 112-129. https://doi.org/10.1177/0959354315616877

Maran, D. A., Varetto, A., Zedda, M., \& Ieraci, V. (2015). Occupational stress, anxiety and coping strategies in police officers. Occupational medicine, 65(6), 466-473. https://doi.org/10.1093/occmed/kqv060 
Maran, D. A., Zedda, M., \& Varetto, A. (2018). Organizational and occupational stressors, their consequences and coping strategies: A questionnaire survey among italian patrol police officers. International Journal of Environmental Research and Public Health, 15(1). https://doi.org/10.3390/ijerph15010166

Maturana, A. P. P. M., \& Valle, T. G. M. (2014). Estratégias de enfrentamento e situações estressoras de profissionais no ambiente hospitalar. Psicol. hosp. (São Paulo), São Paulo, 12(2), 02-23. Recuperado de http://pepsic.bvsalud. org/pdf/ph/v12n2/12n2a02.pdf

Moreno, F. N., Gil, G. P., Haddad, M. C. L., \& Vannuchi, M. T. O. (2011). Estratégias e intervenções no enfrentamento da síndrome de burnout. Rev. enferm. UERJ, Rio de Janeiro, 19(1), 140-145. Recuperado de http://www. facenf.ueri.br/v19n1/v19n1a23.pdf

Parkes, K. (2001). Intervenciones para la gestión del estrés en organizaciones. Em J. Buendía \& F. Ramos (Eds.), Empleo, estrés y salud (pp. 109-129). Madrid: Ediciones Pirámide.

Peiró, J. M., \& Salvador, A. (1993). Control del estrés laboral. Madrid: Eudema, S.A.

Petzold, M. B., Plag, J., \& Ströhle, A. (2020). Dealing with psychological distress by bealthcare professionals during the COV ID-19 pandemia. Der Nervenarzt. https:// doi.org/10.1007/s00115-020-00905-0

Prado, C. E. P. (2016). Estresse ocupacional: causas e consequências. Rev Bras Med Trab, 14(3), 285-9. https://doi.org/10.5327/Z1679-443520163515

Reevy, G. M., \& Deason, G. (2014). Predictors of depression, stress, and anxiety among non-tenure track faculty. Frontiers in psychology, 5, 701. https://doi. org/10.3389/fpsyg.2014.00701

Riolli, L., \& Savicki, V. (2003). Optimism and coping as moderators of the relationship between chronic stress and burnout. Psychological Reports, 92, 1215-1226. https://doi.org/10.2466/pr0.2003.92.3c.1215

Rodrigues, A. B. (2006). Burnout e estilos de coping de enfermeiros que assistem pacientes oncológicos (Tese de doutorado, Universidade de São Paulo, Brasil). https:// doi.org/10.11606/T.7.2007.tde-22032007-091733

Rotenstein, L. S., Ramos, M. A., Torre, M., Segal, J. B., Peluso, M. J., Guille, C., Sen, S., \& Mata, D. A. (2016). Prevalence of depression, depressive symptoms, and suicidal ideation among medical students: a systematic review and meta-analysis. JAMA, 316, 2214-2236. https://doi. org/10.1001/jama.2016.17324

Sanzovo, C. E., \& Coelho, M. E. C. (2007). Estressores e estratégias de coping em uma amostra de psicólogos clínicos. Estud Psicol (Campinas), 24, 227-8. Recuperado de https://www.scielo.br/j/estpsi/a/8JMhXG9gCLDTPpx447 F5hPR/?lang $=$ pt\&format $=$ pdf

Skinner, E. A., Edge, K., Altman, J., \& Sherwood, H. (2003). Searching for the structure of coping: A review and critique of category systems for classifying ways of coping. Psychological Bulletin, 129, 216-269. https://doi. org/10.1037 / 0033-2909.129.2.216

Siqueira, M. M. M. (2005). Esquema mental de reciprocidade e influências sobre afetividade no trabalho. Estudos de Psicologia, Natal, 10(1), 83-93. https://doi. org/10.1590/S1413-294X2005000100010

Steg, L., \& Rothengatter, T. (2017). Introduction to applied social psychology. In L. Steg, A. P. Buunk, \& T. Rothengatter (Eds.), Applied Social Psychology: understanding and managing social problems (Cap. 1, pp. 1-26). Cambridge University Press. Recuperado de http://assets.cambridge. org/97805218/69799/excerpt/9780521869799 excerpt.pdf

Stroebe, W., \& Stroebe, M. (1996). The social psychology of social support. Em E. T. Higgins \& A. W. Kruglanski (Eds.), Social psychology: handbook of basic principles (pp. 597-621). New York, USA: Guilford Press.

Suls, J., David, J. P., \& Harvey, J.H. (1996). Personality and coping: three generations of research. Journal of Personality, 64, 711-735. https://doi. org/10.1111/j.1467-6494.1996.tb00942.x

Taylor, S. E. (2010). Health. Em S. T. Fiske, D. T. Gilbert, \& G. Lindzey (Eds.), Handbook of Social Psychology, 1(5), 698-723. Hoboken, New Jersey, USA: John Wiley \& Sons.

Thoits, P. A. (2011). Mechanisms linking social ties and support to physical and mental health. Journal of Health and Social Behavior, 52(2), 145-161. https:// doi.org/10.1177/0022146510395592

Tohmiya, N., Tadaka, E., \& Arimoto, A. (2018). Cross-sectional study of cognitive stress appraisal and related factors among workers in metropolitan areas of Japan. BMJ Open, 8. https://doi.org/10.1136/ bmjopen-2017-019404

Trindade, L. D. L., Lautert, L., Beck, C. L. C., Amestoy, S. C., \& Pires, D. E. P. D. (2010). Stress and burnout syndrome among workers of the Family Health team. Acta Paulista de Enfermagem, 23, 684-689. https://doi.org/10.1590/ $\underline{\text { S0103-21002010000500016 }}$

Tummers, L. (2017). The relationship between coping and job performance. Journal of Public Administration Research and Theory, 27(1), 150-162. https:// doi.org/10.1093/jopart/muw058

Vaillant, G. E. (1994). Ego mechanisms of defense and personality psychopathology. Journal of Abnormal Psychology, 103, 44-50. https://doi. org/10.1037/0021-843X.103.1.44

Vieira, I. (2010). Conceito(s) de burnout: questões atuais da pesquisa e a contribuição da clínica. Rev Bras Saude Ocup. 35(122), 269-276. https://doi. org/10.1590/S0303-76572010000200009
Yates, P. J., Benson, E. V., Harris, A., \& Baron, R. (2012). An investigation of factors supporting the psychological health of staff in a UK emergency department. Emerg. Med. J. EMJ 29, 533-535. https://doi.org/10.1136/ emj.2010.099630

Zanelli, J. C., Borges-Andrade, J. E., \& Bastos, A. V. B. (2014). Psicologia, Organizações e Trabalho no Brasil (2 $2^{\mathrm{a}}$ ed.). Porto Alegre, Editora Artmed.

Zhang, M., Wang, W., Millar, R., Lil, G., \& Yan, F. (2017). Coping and compromise: a qualitative study of how primary health care providers respond to health reform in China. Human Resources for Health, 15(50). https://doi.org/10.1186/s12960-017-0226-z

Zellars, K. L., \& Perrewé, P. L. (2001). Affective personality and the content of emotional social support: Coping in organizations. Journal of Applied Psychology, 86, 459-467. https://doi.org/10.1037/0021-9010.86.3.459

\section{Informações sobre os autores:}

\section{Jaqueline Marques Muller}

Laboratório de Psicologia Positiva nas Organizações e no Trabalho (LAPPOT)

Universidade Federal de Santa Catarina, Campus Universitário Trindade, Centro de Filosofia e Ciências Humanas, sala 3B 88040-500 Florianópolis, SC, Brasil.

E-mail: jac-muller@hotmail.com

\section{Narbal Silva}

E-mail: narbal.silva@globo.com

\section{Andrea Duarte Pesca}

E-mail: adpesca@gmail.com 